International Journal of Language Education

Volume 4, Number 2, 2020, pp. 183-193

ISSN: $2548-8457$ (Print) 2548-8465 (Online)

Doi: https://doi.org/10.26858/ijole.v4i2.13601

\title{
Association between Oral Error Corrections of University Teacher and English Majors' Language Anxiety in Philippine Higher Education Context
}

\author{
Herford Rei B. Guibangguibang \\ Jose Rizal Memorial State University - Zamboanga del Norte, Philippines \\ Email: herfordreiguibangguibang@gmail.com
}

\begin{abstract}
This study sought to answer the question on the level of English language anxiety in the ESL and mainstream classrooms of 61 total number of English major students utilizing the 20-item self-assessment questionnaire of English Language Anxiety Scale (ELAS) developed by Pappamihiel (2002). Actual onehour footage of classroom was documented through a MONACORR audio-recorder, thrice with each teacher. The recorder was given to one of the teachers' students without knowledge for the authenticity of their oral corrections. After having identified the existing oral error corrections by the English teachers through audio-recording, a self-made questionnaire was answered by the students to find what is the rate of occurrence of the identified oral error correction styles. The frequency count, weighted mean, and Chisquare tests were the statistical tools used to answer the problems posed in this study. Findings divulged after the transcription, teachers were only utilizing elicitation, explicit correction, recast, and repetition. Moreover, students perceived that elicitation oral error correction type is often used while explicit correction, recast, and repetition are only used sometimes by their English teachers. Meanwhile, ELAS results indicate levels of language anxiety in the ESL classes and mainstream, although language anxiety is significantly higher in ESL classes. As to correlation, it was found out that the rate of occurrence of explicit correction, recast, and repetition as perceived by ESL English major students of their English teachers' oral error correction types have no significant relationships to their English language anxiety. This study suggests that oral error correction has nothing to do with the English language anxiety of English major students and that English teachers shall retain the practice of the oral error correction for it does not give high level of learners' anxiety in learning English for undergraduate students choosing English as their major discipline.
\end{abstract}

Keywords: English language anxiety, Oral Error Correction, Elicitation, Explicit Correction, Recast, Repetition

\section{Introduction}

As in any classroom setting, especially in the Philippine situation, oral error correction in English language is inevitable during interaction. However, this practice oftentimes produces varied reactions from the students. Other students readily welcome the oral correction done by the teacher, even if such is made in the middle of an utterance. Yet other students react negatively by shutting up and refraining in oral interaction. 
One of the questions that second language teachers most often address to second language learners is what to do about error correction which is subsumed under the more general term "negative evidence".

Learning does not only depend on the teacher's delivery of lessons, but on the teacher's manner of correcting errors, particularly on verbal communication. According to Mumford and Darn (2020), it is generally agreed that correction is part of the teaching/learning process, but that over-correction and poor correction techniques can be demotivating for the learners. Teachers need to make informed decisions about what, when, and how to correct in order to help learners improve their speaking skills without damaging their confidence. On the course of daily instruction, specifically on oral or verbal interaction, English teachers cannot help but do oral correction when erroneous expressions occur.

Oral correction refers to teacher and peer responses to learner's erroneous production in second language (L2 production ( $\mathrm{Li}, 2018)$. However, oral correction tends to produce anger, inhabitation feelings of inferiority, embarrassment, and a general negative attitude towards the class (Truscott, 1997; cited by Argüelles, Méndez, and Escudero, 2018). This process is called communication apprehension - an individual's level of fear or anxiety associated with either real or anticipated communication with another person or persons (Hashemi, 2016). As explained by McCroskey, communication apprehension is an individual's anxious feelings about communication.

In the early 70's up to the present days, one of the crucial issues in teaching process, more specifically in error correction is how the teacher can correct the learner without de-motivating his learners. According to Tomczyk (2013) as cited by Amalia, Fauziati, and Marmanto (2019), plenty of discussions on errors and corrections in language classroom were still ambiguous because of the fact that the attitudes towards errors of both teachers and students differ, as well as error correction diverge depending on the approaches that are applied.

\section{Literature review}

Oral error correction

Lyster and Ranta (1997) as cited by Simhony and Chanyoo (2018) proposed a model to categorize the types of spoken error correction as explicit correction, recast, clarification request, metalinguistic clues, elicitation, and repetition.

According to this model, clearly indicating that the student's utterance is incorrect then the teacher provides the correct form is an explicit correction style. Meanwhile, recast is without a direct indication that the student's utterance is incorrect, the teacher does implicitly formulate student's error. Another correction style, clarification request refers to the use of phrases like 'excuse me' and 'I don't understand'. Next, metalinguistic feedback is without providing the correct form, the teacher poses questions or provides comments of information related to the student's utterances. Furthermore, one of the oral error corrections, elicitation is that the teacher directly corrects student's errors by asking questions, then reformulates student's utterance. Lastly, repetition style of oral error correction, teacher repeats the student's error then adjusts into intonation to draw student's attention to it.

Additionally, Chaudron (1977), on his Oral Corrective Feedbacks Theory, elaborated the identified six feedback types.

- Explicit Correction. The teacher tells the student he/she is wrong, and then provides the correction. Student: "He eated." Teacher: "No, that's wrong. He ate." 
- Recast. The teacher repeats the student's answer correctly. If a student says, "He eated," the teacher might recast the utterance as, "He ate".

- Clarification Request. The teacher indicates that the student's utterance needs to be repeated or reformulated because it is ill-formed or because the teacher misunderstands it. If the student says, "He walk to the shore," the teacher might respond, "what?".

- Metalinguistic Feedback. The teacher repeats student's comments, intonation, or asks questions related to a problem in the learner's utterance but without providing the correct form. For example, a metalinguistic indicator to a student of a grammar error in use of third person singular "s" might be: "No. You need to put an "s" on the verb if the subject is he, she, or it."

- Elicitation. The teacher uses various strategies to elicit the correct form from the student. If student says, "Yesterday, he walks to school", the teacher might: (1) repeat the beginning of the student's utterance and elicit completion by pausing meaningfully to encourage the student to "fill in the blank," at the point where the error occurred: "No, Yesterday he ..."(2) ask a question to elicit a correct form: "How do we talk about the past in English?"(3) ask a learner to reformulate his or her own utterance: "Please say that again correctly".

- Repetition. The teacher repeats a learner's incorrect utterance, usually with marked intonation or volume to highlight the error. Student: "He eated." Teacher: "He eated?" (with strong question intonation to draw attention to the error).

English language anxiety

It has been widely accepted that many if not most language learners face intrapersonal diffuculties in second/foreign language learning, anxiety is one of them. Anxiety is identified as a distinct affective variable in second language research. According to Tanveer (2007) as cited by Zheng and Cheng (2018) that feeling of anxiety is one of the commonly expressed by second/foreign language learners in the learning speaking a second/foreign language and also considered to exert a negative effect on communication to the target language.

Hashemi (2011) as cited by Jugo (2020) states that language anxiety, in social context, may be experienced due to extrinsic motivators such as different social and cultural environments, particularly the environments where L1 and L2/FL learning takes place. In the study of Huang, Eslami, and $\mathrm{Hu}$ (2010) as cited by (Odoy, 2018) on the relationship between support (from teachers and peers) and the foreign language learners' anxiety which involved 158 adult Taiwanese English-language learners reveals that language learners felt less anxious when they perceived that they obtained more academic support from their teachers.

In the study of Khattak, Jamshed, Ahmad, and Baig (2011) as cited by Khan (2015), by a semi-structured interviews with the 10 volunteer students from English Department at Abdul Wali Khan University Mardam (AWKUM) Pakistan showed that students felt anxious of making mistakes and about teachers' correcting their mistakes in the classes.

On the other hand, English language learning anxiety can be coped up with different coping strategies according to the study conducted by Kao and Craigie (2013) as cited by Tulgar (2018) which found out that positive thinking was the coping strategy that the participants used most often when they were experiencing foreign language learning anxiety.

In the Philippines, Filipinos learn English as a second language not as a foreign language. ESL and EFL learners have great disparities, particularly on the pedagogical approaches by their teachers. An investigation on the anxiety attributions of beginning public speaking Filipino students in the state-run university was conducted by Del Villar (2010) as cited by Marcial (2016). 
Her findings revealed that there are eight factors that students attribute their anxiety to. These are expectation, training and experiences, audience, self-worth, rejection, verbal, fluency, preparation and previous pleasant experience. Further, she states that oral communication apprehension is one of the most studied phenomena among Western communication researchers. There is still a dearth of research data on Filipinos considering oral communication anxiety's overwhelming impact on speakers. Thus, this study is conducted.

\section{Research method}

The respondents of the study were sixty-one (61) English major students in ESL and mainstream classes for the English language anxiety, and their seven (7) English teachers for the oral error corrections.

This study employed the descriptive-correlational research method. It is descriptive in nature since it provided a snapshot of the current state of the oral correction styles being utilized by the English instructors and the English Language anxiety level of the English major students. Further, it is correlational study because it tried to determine the significant relationship or association between the oral error corrections of how often these were being used to the English Language anxiety level of the English major students.

\section{Data gathering}

Prior the conduct of the study, both groups of respondents were informed about the study and were able to sign consent forms. They were also knowledgeable on the proceedings and purpose of the study. After the orientation, sixty-one (61) English major students were then provided with the English Language Anxiety Scale (ELAS) research questionnaire to gather data on their English language anxiety level in the ESL and mainstream classroom. ELAS is composed of 20 items self-assessment developed by Pappamihiel (2002) following the scale: 1- strongly disagree, 2- disagree, 3 - neutral, $4 \quad$-agree, and 5 - strongly agree. ELAS questionnaire was a modification developed from the FLCAS (Foreign Language Classroom Anxiety Scale) by Horwitz et al. (1986) in order to get the validity of the test items since FLCAS is appropriate for learners of English as a Foreign Language not for English as a Second Language. The student respondents were given ample time to finish answering the questionnaire and the researcher made sure that the student respondents were answering at the most convenient environment. Questionnaires were then retrieved after the student respondents have done answering the ELAS, however, the researcher made sure first if all items were answered before the respondents took their exits. Then, the researcher tallied and run the necessary statistical tools for analysis and interpretation of the data collected. In order to interpret the data for English Language Anxiety level, the following continuum was used for the mean scores: Above 4 - High Anxiety Level; 3 to 4 - Medium Anxiety Level; Below 3 - Low Anxiety Level.

Meanwhile, in gathering the data on the seven (7) English teachers' oral error corrections used, actual one-hour footage of classroom was documented through a MONACORR audiorecorder, thrice with each teacher. The recorder was given to one of the teachers' students without knowledge for the authenticity of their oral corrections.

However, prior information was disseminated that there will be an actual classroom recording for research purposes, and everyone was amenable in order to take measures of ethicality. With all the needed data, the researcher then proceeded to the transcription. Each recording was transcribed thoroughly with the help of audio professional/expert for the clarity of the conversation documented. The researcher consulted second expert for the validity of the transcription and 
presented that all transcribed from the recordings were accurate. Then, after the researcher identified the English teachers' oral error correction used, a self-made questionnaire was then crafted in order to determine the perception of the students on the rate of occurrence of the identified oral error corrections with the following continuum: 1 - Never (never been corrected per meeting in the class); 2 - Rarely (at least 1 to 3 times been corrected per meeting in the class); 3 Sometimes (at least 4 to 6 times been corrected per meeting in the class); 4 - Often ( at least 7 to 9 times been corrected per meeting in the class); 5 - Always (more than 10 times been corrected per meeting in the class). The researcher then again asked the student-respondents to answer the said self-made questionnaire in order to find out what is the rate of occurrence of the identified oral error corrections used by their English teachers in their classes. Ample and convenient time were given to the student-respondents in answering the questionnaire in order to ensure the validity of their responses. After answering, the questionnaires were then retrieved, tallied, and computed for analysis and interpretation.

Data collected from the respondents were treated with utmost confidentiality as reflected on the consent forms with terms and conditions established by the researcher and the respondents prior the conduct of the study.

Statistical tools

Frequency count, weighted mean, and Chi-square tests were the statistical tools used to answer the problems posed in this study.

The following are the research problems:

1. What are the different types of oral error corrections used by English teachers?

2. How often do teachers correct students?

3. What is the level of anxiety of the students?

4. Is there a significant relationship between the type of oral correction and the level of anxiety of the students?

\section{Results}

Table 1. The different types of oral error corrections used by the English instructors

\begin{tabular}{|c|l|l|}
\hline Teacher & Student's utterance \\
\hline T1 & "Last night, the boy walks silently in the plaza" & "Last night, the boy..." \\
\hline T2 & "She buy the foods at the cafeteria..." & "How do we use verb if the subject is singular?" \\
\hline T3 & "The language are inseparable to culture..." & "(calls the name), please say it again correctly." \\
\hline T6 & "I cannot argues to his opinion because..." & "Again, please say the correct form." \\
\hline Teacher & Student's utterances & Explicit \\
\hline T4 & "She eated..." & "Wrong, that's she ate." \\
\hline T5 & "The well ('wel) of the cart symbolizes..." & "It is now well ( wel), it is pronounced as wheel \\
('(h)wēl).
\end{tabular}




\begin{tabular}{l|l|l|} 
T2 & "Syntak is..." & "Syntak!" (repeated the word with strong intonation) \\
T4 & "Well, one of our member..." & "member?” (strong intonation) \\
\hline
\end{tabular}

The table 1 shows the different types of oral error corrections being utilized by the English instructors. Among the six (6) oral error corrections, only four (4) were being observed in the transcription: Elicitation, Explicit, Recast, and Repetition. It is notable that the metalinguistic feedback and clarification request oral error correction types were not being observed. Further, it can be seen that most of the teachers used elicitation and recast oral correction types since there were four (4) out of seven (7) teachers prevalently utilizing it than the remaining identified types - explicit and repetition, since only three (3) out of seven (7) teachers.

This result of the study implies that these English teachers teaching ESL students are not practicing the metalinguistic feedback and clarification request oral error correction types. They are more on the practice of elicitation, explicit, recast, and repetition types. Since, not even once that metalinguistic feedback and clarification request oral error correction types were present after the transcription. This suggests that these English teachers are comfortable using the remaining types.

Another finding of this study, as can also be gleaned in the transcript, the errors committed by the students were not just limited to grammar and mechanics but also the correct pronunciation of the words, e.g. correct: wheel (' $h$ weell), error: well ('wel); .correct: law (ló), error low (lō). This implies that these English teachers usually correct ESL students on the pronunciation and the grammar structure mistakes committed.

Table 2. The rate of occurrence of the oral error corrections of the English teachers as perceived by their English major students

\begin{tabular}{|c|c|c|}
\hline Oral Error Corrections & \multicolumn{2}{c|}{ Rate of Occurrence } \\
\cline { 2 - 3 } & Mean & Description \\
\hline Elicitation & 3.6 & Often \\
\hline Explicit & 3.0 & Sometimes \\
\hline Recast & 3.0 & Sometimes \\
\hline Repetition & 3.0 & Sometimes \\
\hline
\end{tabular}

\begin{tabular}{|c|c|c|c|}
\hline $\begin{array}{l}\text { Rating } \\
\text { Scale }\end{array}$ & Description & $\begin{array}{l}\text { Rating } \\
\text { Value }\end{array}$ & Qualification \\
\hline 1 & Never & $\begin{array}{l}1.00- \\
1.80\end{array}$ & Never been corrected per meeting in the class \\
\hline 2 & Rarely & $\begin{array}{l}1.81- \\
2.60\end{array}$ & At least 1 to 3 times been corrected per meeting in the class \\
\hline 3 & Sometimes & $\begin{array}{l}2.61- \\
3.40\end{array}$ & At least 4 to 6 times been corrected per meeting in the class \\
\hline 4 & Often & $\begin{array}{l}3.41- \\
4.20\end{array}$ & At least 7 to 9 times been corrected per meeting in the class. \\
\hline 5 & Always & $\begin{array}{l}4.21- \\
5.00\end{array}$ & More than 10 times been corrected per meeting in the class. \\
\hline
\end{tabular}

Table 2 presents the rate of occurrence of the oral error corrections of the English teachers as perceived by their English major students. It reveals that among the identified oral error correction types: Elicitation, Explicit, Recast, and Repetition, only Elicitation obtained the highest mean of 3.6 while the remaining three types got similar mean of 3.0. This means that, only 
elicitation oral error correction is often used by their teachers than the Explicit, Recast, and Repetition types. Implying that these English teachers directly correct student's errors by asking questions, then reformulates student's utterance.

Table 3. The level of English language anxiety of the English major students

\begin{tabular}{|l|c|c|}
\hline \multirow{2}{*}{ English Language Classes } & \multicolumn{2}{c|}{ English Language Anxiety Level } \\
\cline { 2 - 3 } & Mean & Description \\
\hline ESL classes & 3.4 & Medium Anxiety Level \\
\hline Mainstream classes & 3.2 & Medium Anxiety Level \\
\hline Weighted Mean & $\mathbf{3 . 3}$ & Medium Anxiety Level \\
\hline
\end{tabular}

Note:

Continuum: Description:

Above $4 \quad$ High Anxiety Level

3-4 Medium Anxiety Level

Below 3 Low Anxiety Level

Table 3 exhibits the the ELAS results indicate levels of language anxiety in the ESL classes and mainstream classes of English major students. It can be noted that both classes are described having medium anxiety level with means of 3.4 and 3.2 respectively. However, it can also be gleaned that English language anxiety is significantly higher in ESL classes.

Table 4. Test of relationship between the types of oral error correction of the English teachers and the level of anxiety of the English major students

\begin{tabular}{|l|l|l|l|l|l|}
\hline $\begin{array}{l}\text { Oral Error } \\
\text { Correction }\end{array}$ & $\begin{array}{l}\text { English } \\
\text { Lang. } \\
\text { Anxiety }\end{array}$ & $\mathbf{x}^{\mathbf{2}}$ & df & $\begin{array}{l}\text { P-value } \\
\text { @ 0.05 } \\
\text { level of } \\
\text { sig. }\end{array}$ & Interpretation \\
\hline Elicitation & $\begin{array}{l}\text { Med. } \\
\text { Level }\end{array}$ & $8.850^{\mathrm{a}}$ & \multirow{2}{*}{1} & 0.065 & Not Significant \\
\hline Explicit & $\begin{array}{l}\text { Med. } \\
\text { Level }\end{array}$ & $12.710^{\mathrm{a}}$ & & .311 & Not Significant \\
\cline { 1 - 2 } \cline { 5 - 6 } & $\begin{array}{l}\text { Med. } \\
\text { Level }\end{array}$ & $12.998^{\mathrm{a}}$ & & .129 & Not Significant \\
\hline Repetition & $\begin{array}{l}\text { Med. } \\
\text { Level }\end{array}$ & $8.256^{\mathrm{a}}$ & & .194 & Not Significant \\
\hline
\end{tabular}

Table 4 presents the relationship between the types of oral error correction of the English teachers and the level of anxiety of the English major students. It reveals that the rate of occurrence as perceived by ESL English major students of their English teachers' oral error correction styles: elicitation, explicit correction, recast, and repetition have no significant relationships to their English language anxiety tested at 0.05 level of significance.

\section{Discussions}

English teachers' oral error correction used

In correcting English major students both from mainstream and ESL classrooms, it is found that among the oral correction types, there were only four (4) were being used by the English 
teachers during their actual teaching process: Elicitation, Explicit, Recast, and Repetition. This implies that these English teachers teaching English major students are not practicing the metalinguistic feedback and clarification request oral error correction types. They are more on the practice of elicitation, explicit, recast, and repetition types. Since, not even once that metalinguistic feedback and clarification request oral error correction types prevailed after the transcription. This suggests that these English teachers are comfortable using the remaining types. Noted also that the corrections made by these English teachers are not just limited on correcting erroneous grammar but also the mispronunciation of their English major students. Implying that the oral error corrections made were not focused on one aspect of English language but the whole as to: the correct structure of the sentence (grammar), enunciation (pronunciation), and even diction. Meaning, when errors (in all kinds) comes out from the English major students verbally, their English teachers provide the corrections using the identified oral correction types.

Moreover, of the four (4) identified types, as perceived by their English major students, Elicitation is observed often used, while the others were sometimes. This implies that the English teachers in one of the universities in the Philippines are more aware, limited and comfortable in elicitation type of oral error correction. Since as perceived by their English major students (both from mainstream and ESL classrooms), they were corrected by these teachers in 7 to 9 times per meeting in the class. This is somewhat not congruent with the result of the study conducted by Shirkhani and Tajeddin (2016) on the detailed analysis of around 128 hours of classroom interactions revealing that explicit correction is the most frequent of all oral error corrections.

\section{English language anxiety level of English major students}

On the other hand, the English language anxiety level of the English major students is only in medium level, although data were categorized by two of their classes: ESL class and their mainstream class, still their anxiety never changed. This imply that, these students, having English as their major discipline, even feel anxiety but not too much regardless of what class they attend.

Core Aim: Correlation between the rate of occurrence of Oral Error Correction Types and English Language Anxiety

Lastly, when the rate of occurrence of the four (4) identified oral error correction types utilized by English teachers were correlated to the English language anxiety level both perceived by the English major students reveals that there are no significant relationships. Implying that the oral error correction types being applied by the English teachers will not affect English major students' language anxiety which English language in this context is taught and learned as a second language. Further, this also imply that English major students (both from mainstream and ESL classrooms) are immune to oral error corrections and that they readily welcome these corrections when they commit mistakes grammatically or in pronunciation - like tools in learning the English language. This finding is in contrary to Hendrickson as cited by Calsiyao (2015) that learners do not like to be corrected for each minor error they make because this practice ruins their confidence to use the target language.

\section{Conclusion}

This study revealed that English major students in an undergraduate study in one of the universities in the Philippines still experience English language anxiety both in ESL classes and mainstream classes. They still experience the language anxiety but not too much only in medium level. On the other hand, this also revealed that among the oral error correction types, only four 
(4) were present: elicitation, explicit, recast, and repetition were used by English instructors in their pedagogical process. Also, English teachers do not just limit their oral error corrections to grammatical mistakes of the students but they correct when mispronunciation of words occur and even diction. On the core aim of the study, the test of the significant relationship of the rate of occurrence of the identified oral error correction types of the English teachers to the English major students' English language anxiety exposes that there are no significant relationships. Giving the implication that English major students are immune to oral error corrections and these learners believed that these practices are tools in English language learning. So, this study suggests that oral error correction has nothing to do with the English language anxiety of English major students (both in mainstream and ESL classrooms) and that English teachers shall retain the practice of the oral error correction for it does not give high level of learners' anxiety in learning English for undergraduate students choosing English as their major discipline.

\section{Declaration of conflicting interest}

The authors state that there is no conflict of interest concerning the publication of this paper.

Funding Acknowledgment:

There is no funding received for this project

\section{References}

Agudo, J. M. (2013). An investigation into how EFL learners emotionally respond to teachers' oral corrective feedback. Colombian Applied Linguistics Journal, 15. doi:10.14483/udistrial.jour.calj.2013.2.a08

Amalia, Z. D., Fauziati, E., \& Marmanto, S. (2019). Male and Female Students' Preferences on the Oral Corrective Feedback in English as Foreign Language (EFL) Speaking Classroom. Humaniora. doi:https://doi.org/10.21512/humaniora.v10i1.5248

Argüelles, L. G., Méndez, E. H., \& Escudero, M. P. (2018). EFL Teachers' Attitudes Towards Oral Corrective Feedback: A Case Study. Profile: Issues in Teachers'Professional Development. doi:https://doi.org/10.15446/profile.v21n1.69508

Hashemi, M. (2011). Language stress and anxiety among the English language learners. Procedia-Social and Behavioral Sciences, 1811-1816.

Huang, S., Eslami, Z., \& Hu , R.-J. (2010). The Relationship between Teacher and Peer Support and English-Language Learners' Anxiety. English Language Teaching, 32-40.

Jugo, R. (2020). Language Anxiety in Focus: The Case of Filipino Undergraduate Teacher Education Learners. Education Research International. doi:10.1155/2020/7049837

Kao, P.-C., \& Craigie, P. (2013). Coping strategies of Tawanese university students as predictors of English language learning anxiety. Social Behaviour and Personaloty: an international journal, 41(3), 411-419. 
Khan, S. M. (2015). Influence of Speech Anxiety on Oral Communication Skills among ESL/EFL Learners. Institute of Education Sciences, 49-53. Retrieved from https://eric.ed.gov/?id=EJ1127504

Khattak, Z., Jamshed, T., Ahmad, A., \& Baig, M. (2011). An investigation into the causes of English language learning anxiety in students at AWKUM. Procedia-Social and Behavioral Sciences, 1600-1604.

Li, S. (2018). Oral Corrective Feedback. ELT Journal, 68(2), 196-198. doi:https://doi.org/10.1093/elt/cct076

Lyster, R., \& Ranta, L. (1997). Corrective feedback and learner uptake: Negotiation in communication classrooms. Studies on Second Language Acquisition, 37-66. Retrieved from Digital.library.mchill.ca/R/files/roy/lyster_ranta1997_SSLA.pdf

Marcial, A. K. (2016). Learner variables and language anxiety in oral communication: The case of University students in the Philippines. International Online Journal of Education and Teaching (IOJET), 285-301. doi:Online Journal of Education and Teaching (IOJET

Mumford , S., \& Darn, S. (2020). Classroom management: Speaking correction techniques. Macmillan Education Limited. Retrieved from http://www.onestopenglish.com/methodology/teaching-articles/classroommanagement/classroom-management-speaking-correction-techniques/146455.article

Odoy, J. (2018). Teacher-Peer Support and Learning Behavior of High School Students. 1st International Conference on Psychology, Counselling and Education (ICPCE 2018). New Era University, Manila, Philippines.

Pappamihiel, E. (2002). English as a Second Language Students and English Language Anxiety: Issues in the Mainstream Classroom. Research in the Teaching of English, 36.

Shirkhani, S., \& Tajeddin, Z. (2016). L2 teacher's explicit and implicit corrective feedback and its linguistic focus. Iranian Journal of Applied Linguistics, 19(1), 181-206.

Simhony, J., \& Chanyoo, N. (2018). A Comparison of Corrective Feedback Used in International and EFL Contexts. Journal of Language Teaching and Research. doi:http://dx.doi.org/10.17507/jltr.0903.17

Tanveer, M. (2007). Investigation of the factors that cause language anxiety for ESL/EFL learners in learning speaking skills and the influence it casts on communcation in the target language.

Tomczyk, E. (2013). Perceptions of oral errors and their corrective feedback: teachers vs. students. Journal of Language Teaching and Research, 4(5), 924-931. Retrieved from https://pdfs.semanticsscholar.org/cf5f/7a7b7a669579747e4b5d8f381f4c5fbc6c00.pdf

Tulgar, A. T. (2018). Speaking anxiety of foreign learners of Turkish in target context. International Online Journal of Education and Teaching (IOJET), 5(2), 313-332. doi:http://iojet.org/index.php/IOJET/article/view/362/237 
Zheng, Y., \& Cheng, L. (2018). How does anxiety influence language performance? From the perspectives of foreign language classroom anxiety and cognitive test anxiety. Lang Test Asia. doi:https://doi.org/10.1186/s40468-018-0065-4 